\title{
Effect of inhaled budesonide on seasonal changes in sensitivity and maximal response to methacholine in pollen-sensitive asthmatic subjects
}

\author{
L. Prieto*, J.M. Bertó*, V. Gutiérrez*, C. Tornero**
}

Effect of inhaled budesonide on seasonal changes in sensitivity and maximal response to methacholine in pollen-sensitive asthmatic subjects. L. Prieto, J.M. Bertó, V. Gutiérrez, C. Tornero. (CERS Journals Ltd 1994.

ABSTRACT: The aim of this study was to investigate the effect of inhaled budesonide on modifications of the provocative concentration of agonist causing a $20 \%$ fall in forced expiratory volume in one second $\left(\mathrm{FEV}_{1}\right)\left(\mathrm{PC}_{20}\right)$ and maximal response plateau to inhaled methacholine during the pollen season in pollen-sensitive subjects with mild asthma.

The effects of inhaled budesonide $\left(800 \mu \mathrm{g} \cdot \mathrm{day}^{-1}\right)$ on the threshold value $\left(\mathrm{PC}_{20}\right)$ and maximal response plateau to inhaled methacholine were studied in 28 pollen-sensitive subjects with mild asthma during a pollen season in a randomized, doubleblind, placebo-controlled parallel fashion. They were challenged with methacholine (up to $200 \mathrm{mg} \cdot \mathrm{ml}^{-1}$ ) in February (preseasonal assessment) and during the middle of the pollen season (in May and again in June).

Subjects treated with budesonide $(n=13)$ were protected from the decrease in $\mathbf{P C}_{20}$ seen in the placebo $(n=15)$ group (geometric mean $\mathrm{PC}_{20}$ placebo group: preseasonal=8.51, May=2.19 and $\mathrm{June}=1.78 \mathrm{mg} \cdot \mathrm{ml}^{-1}$; budesonide group: preseasonal=3.71, May=3.23 and $J u n e=2.40 \mathrm{mg} \cdot \mathrm{ml}^{-1}$; intergroup differences in doubling concentrations, $\mathbf{p}<0.05$ ). Among 10 subjects in the placebo group who reached plateau during the preseasonal assessment, seven lost the plateau in May and six in June. In the budesonide group, among seven subjects who reached plateau during the preseasonal assessment, three lost the plateau in May and four in June. Between-group differences were not significant.

We conclude that in pollen-sensitive subjects with mild asthma, inhaled budesonide blocks the effects of natural allergen exposure on the methacholine threshold value. However, we were not able to show a significant protection against the pollen-induced changes on the maximal response plateau.

Eur Respir J., 1994, 7, 1845-1851.
*Unidad de Alergia and **Servicio de M. Interna, Hospital Dr. Peset, Valencia, Spain.

Correspondence: J.L. Prieto

Unidad de Alergia

Hospital Dr. Peset

C/ Juan de Garay 21

46017 Valencia

Spain

Keywords: Airway responsiveness asthma

glucocorticosteroids

methacholine

maximal response plateau

Received: February 21994

Accepted after revision June 121994
There is convincing evidence $[1,2]$ that, in sensitized asthmatic subjects, natural allergen exposure during a pollen season results in increased airway responsiveness, and drugs with anti-inflammatory properties, such as methylprednisolone [2], sodium cromoglycate [3], nedocromil sodium [4], and nasal beclomethasone [5] protect against this seasonal increase in airway responsiveness. In these studies, the bronchoconstriction induced by the pharmacological agent was measured in a dose-response fashion, and the airway responsiveness was expressed as the provocative concentration of agonist causing a $20 \%$ fall in forced expiratory volume in one second $\left(\mathrm{FEV}_{1}\right)\left(\mathrm{PC}_{20}\right)$. However, from the clinical standpoint, airway hyperresponsiveness can be regarded as the tendency of the airways to narrow too easily and too much. Thus, assessment of bronchial responsiveness requires not only a threshold response to an inhaled agonist but an overall assessment of the shape of the curve [6, 7].

Inhaled glucocorticosteroids have proved to be at least as effective as nedocromil sodium or sodium cromoglycate at reducing the provoked increase in airway responsiveness following allergen challenge in the laboratory [8]. However, it is not known whether inhaled corticosteroids protect against the seasonal increase in bronchial responsiveness induced by natural allergen exposure.

In a previous study [9], we have shown that in pollensensitive asthmatic patients the cessation of exposure to pollen is associated with a significant increase in methacholine $\mathrm{PC}_{20}$ and decrease in the maximal response-plateau level. In the current study, we investigate the effect of inhaled corticosteroid therapy on modifications of $\mathrm{PC}_{20}$, and maximal response to inhaled methacholine during the pollen season in sensitized subjects with asthma. 


\section{Subjects and methods}

\section{Subjects}

Thirty nonsmoking subjects (8 males) aged 15-52 yrs, from our out-patient Allergy Clinic, were studied, having met the following inclusion criteria: a history of mild seasonal asthma [10] for at least $2 \mathrm{yrs}$; an $\mathrm{FEV}_{1}$ greater than $80 \%$ of the predicted value; a positive skinprick test ( $\geq 3 \mathrm{~mm}$ wheal diameter) to grass and/or Parietaria pollens and no skin sensitization for other allergens tested, namely olive, house dust mites, Alternaria, Aspergillus, Neurospora, Penicillium, Cladosporium, and cat and dog dander (Abelló S.A., Madrid, Spain). Patients with significant renal, hepatic or cardiovascular disease, pregnant women, and subjects having experienced chest infections within 4 weeks before the start of the study, were excluded. Out of the pollen season, these subjects had no asthma symptoms and none had taken bronchodilators, inhaled steroids (nasal or bronchial) or other respiratory anti-inflammatory drugs within 5 months before the first evaluation.

The study was approved by the Hospital Medical Assays Committee and all subjects gave their informed consent.

\section{Study design}

In our region $[9,11]$, the concentration of Urticaceae (Parietaria) pollen increases in April, and peaks between May and the beginning of September. Data on grass pollen indicate that the concentration increases in April and plateaus between May and July.

We used a randomized, double-blind, placebo-controlled, parallel study design. Subjects were first evaluated in February 1993, before the pollen season (preseasonal assessment), when baseline pulmonary function and methacholine bronchial challenge were performed. They were then randomized to receive budesonide (Olfex $\mathrm{Bu}-$ cal, Aristegui, Bilbao, Spain) $400 \mu g$ b.i.d. or placebo, which they commenced taking in March. Budesonide and placebo were administered using a metered-dose inhaler (MDI) with a $750 \mathrm{ml}$ spacer device (Inhalventus, Aldo-Union, Barcelona, Spain). One puff of the preparation contained $200 \mu \mathrm{g}$ of budesonide. Patients were instructed to take their study medication upon awakening and approximately $12 \mathrm{~h}$ later, and were trained during the first and every follow-up visit to use the MDI and spacer correctly. New study drugs were dispensed at each visit. At subsequent visits the canisters were returned and weighed. Treatment compliance was reported as the actual canister weight loss as a percentage of the expected weight loss. The latter was estimated from the known weight loss per dose and the number of doses prescribed.

Salbutamol MDI (Ventolin, Glaxo, Madrid, Spain) and/or terfenadine (Rapidal, Aristegui, Bilbao, Spain) and/or sodium cromoglycate eye drops (Cusicrom, Cusi S.A., Barcelona, Spain) were used on an "as needed" basis to control their pulmonary, nasal, or eye symptoms, respectively. Subjects were asked not to take salbutamol for at least $8 \mathrm{~h}$ and terfenadine for at least $72 \mathrm{~h}$ before each challenge.

Subjects returned to the laboratory at the height of the pollen season (seasonal assessment) in May and again in June (after 8 and 12 weeks of treatment), having taken their last dose of trial medication the evening before. Spirometry and methacholine bronchial challenges were performed by personnel blinded to the earlier challenge results.

\section{Measurement of bronchial responsiveness}

Spirometry was performed [12] on a dry rolling seal spirometer (PFT Horizon System Two, Sensormedics Co., Anaheim, CA, USA). On each test day, baseline $\mathrm{FEV}_{1}$ and forced vital capacity (FVC) were determined as the best of three consecutive measurements that agreed within 5\%. Reference values of CRAPO et al. [13] were used for young patients (15-25 yrs of age) and those of the European Community for Coal and Steel [14] for subjects aged over 25 yrs. Each patient was required to have an $\mathrm{FEV}_{1}$ of at least $80 \%$ of the predicted value and no more than a $7 \%$ fall in $\mathrm{FEV}_{1}$ after inhalation of phosphate-buffered saline (PBS). Moreover, the variation in the prechallenge $\mathrm{FEV}_{1}$ on the three study days had to be within $10 \%$.

Methacholine provocation tests were performed using a tidal breathing method adapted from CосKCROFT et al. [15]. Aerosols were delivered by a Hudson 1720 nebulizer (Temecula, CA, USA) with $2 \mathrm{ml}$ of test solution in the container and operated by oxygen (mean \pm SD nebulizer output, $\left.0.19 \pm 0.018 \mathrm{ml} \cdot \mathrm{min}^{-1}\right)$. The nebulizer was connected directly to a mouthpiece, a noseclip was worn, and the aerosol was inhaled through the mouth by tidal breathing for 2 min. After inhalation of PBS, subjects inhaled doubling concentrations of methacholine (Sigma Chemical, St. Louis, MO, USA) from 0.095 to $200 \mathrm{mg} \cdot \mathrm{ml}^{-1}$, diluted in PBS. Subjects were experienced at performing forced expiratory manoeuvres, and a single determination of $\mathrm{FEV}_{1}$ was taken 60-90 s after each methacholine concentration [16], unless the trace was uninterpretable because of cough. The challenge was stopped when the $\mathrm{FEV}_{1}$ dropped by more than $50 \%$ from the post-PBS value or when the highest concentration of methacholine had been administered.

Dose-response curves were plotted for each challenge test as the percentage fall in $\mathrm{FEV}_{1}$ against the log methacholine concentration and were characterized by their threshold value $\left(\mathrm{PC}_{20}\right)$, and if possible, by their maximal response plateau.

\section{Data analysis}

Methacholine $\mathrm{PC}_{20}$ was calculated from the log concentration-response curves by linear interpolation of the two adjacent data points. A $\mathrm{PC}_{20}$ value of $200 \mathrm{mg} \cdot \mathrm{ml}^{-1}$ was assigned to six subjects (three in each group) in the preseasonal assessment, and to two subjects (budesonide 
group) in May, in whom $\mathrm{FEV}_{1}$ dropped less than $20 \%$ even when the highest concentration of methacholine was used. All $\mathrm{PC}_{20}$ values were log-transferred before analysis. Changes in $\mathrm{PC}_{20}$-methacholine between the three study periods were also expressed in terms of doubling concentrations of methacholine calculated as $\Delta \log \mathrm{PC}_{20} / \log 2$. Changes in prechallenge $\mathrm{FEV}_{1}$, and methacholine $\mathrm{PC}_{20}$ were assessed by analysis of variance of repeated measurements within each randomized group, and by an unpaired t-test to compare between groups.

A maximal response plateau was defined when three or more of the highest concentrations of methacholine produced no further fall in $\mathrm{FEV}_{1}$ (within $5 \%$ response ranges). The level of the maximal response was obtained [17] by averaging the data points on the plateau. The prevalence of plateau in each period was compared by the Fisher's exact test. Based on previous data [9], the power of our analysis to detect a $50 \%$ difference in the proportion of patients who lost the plateau during the pollen season was $65 \%$ with a level of significance of 0.05 .

\section{Results}

Of the 30 subjects initially recruited, two (budesonide group) were withdrawn from the study before the completion of the first month of treatment. One patient declined the previous acceptance of participation, whilst the other withdrew due to pregnancy. Only the data for the remaining 28 subjects who completed the study period were included in the final analysis. Of those who completed, 13 were randomized to receive budesonide and 15 to receive placebo. The two groups (table 1) did not differ with respect to age, sex, pulmonary function, skin sensitization, or bronchial responsiveness $\left(\mathrm{PC}_{20}\right.$ and prevalence or level of plateau). Those taking budesonide started with greater bronchial responsiveness

Table 1. - Subject characteristics at enrolment

\begin{tabular}{lcc}
\hline Characteristic & Placebo & Budesonide \\
\hline Subjects n & 15 & 13 \\
Age yrs* & $35 \pm 2$ & $33 \pm 3$ \\
Sex M/F & $4 / 11$ & $4 / 9$ \\
Skin sensitization & & \\
$\quad$ Grass & 7 & 5 \\
$\quad$ Parietaria & 6 & 5 \\
$\quad$ Grass + Parietaria & 2 & $101 \pm 3$ \\
FEV $_{1} \%$ pred* & $102 \pm 3$ & $3.7(0.15-200)$ \\
PC $_{20}$ mg-ml-1\# & $8.5(0.42-200)$ & $7 / 6$ \\
Plateau yes/no $_{\text {Level of plateau* }}$ & $10 / 5$ & $26.0 \pm 3.1$ \\
$\quad \%$ FEV & $24.8 \pm 4.8$ &
\end{tabular}

$\mathrm{PC}_{20}$ : provocation concentration of methacholine producing a $20 \%$ fall in $\mathrm{FEV}_{1} ; \mathrm{FEV}_{1}$ : forced expiratory volume in one second; level of plateau: average of the data points on the plateau in the seven subjects of the budesonide group and 10 subjects of the placebo groups in whom plateau was detected. *: data presented as mean \pm SEM; \#: data presented as geometric mean and range in parenthesis.
Table 2. - $\mathrm{FEV}_{1}(l)$ values before methacholine challenge in each period and treatment compliance for the two treatment groups

\begin{tabular}{|c|c|c|c|c|}
\hline \multirow{2}{*}{$\begin{array}{l}\text { Subj. } \\
\text { No. }\end{array}$} & \multirow{2}{*}{$\begin{array}{c}\text { Preseasonal } \\
\text { assessment }\end{array}$} & \multicolumn{2}{|c|}{ Seasonal assessment } & \multirow{2}{*}{$\begin{array}{l}\text { Compliance } \\
\% \text { expected }\end{array}$} \\
\hline & & May & June & \\
\hline \multicolumn{5}{|c|}{ Placebo group } \\
\hline 1 & 3.10 & 2.92 & 2.93 & 92 \\
\hline 2 & 4.34 & 3.97 & 4.16 & 81 \\
\hline 3 & 4.52 & 4.52 & 4.39 & 70 \\
\hline 4 & 2.70 & 2.90 & 2.92 & 86 \\
\hline 5 & 2.83 & 3.02 & 3.11 & 101 \\
\hline 6 & 3.68 & 3.79 & 3.68 & 66 \\
\hline 7 & 3.61 & 3.48 & 3.46 & 99 \\
\hline 8 & 3.63 & 3.73 & 3.73 & 85 \\
\hline 9 & 3.29 & 3.28 & 3.12 & 68 \\
\hline 10 & 3.34 & 3.40 & 3.26 & 89 \\
\hline 11 & 4.30 & 4.30 & 4.32 & 97 \\
\hline 12 & 2.95 & 2.74 & 2.69 & 91 \\
\hline 13 & 4.27 & 4.56 & 4.48 & 83 \\
\hline 14 & 2.63 & 2.62 & 2.64 & 137 \\
\hline 15 & 3.30 & 3.31 & 3.40 & 95 \\
\hline Mean & 3.50 & 3.50 & 3.48 & 89 \\
\hline SEM & 0.16 & 0.16 & 0.16 & \\
\hline \multicolumn{5}{|c|}{ Budesonide group } \\
\hline 16 & 2.86 & 2.85 & 2.69 & 98 \\
\hline 17 & 2.60 & 2.52 & 2.70 & 91 \\
\hline 18 & 4.72 & 4.62 & 4.72 & 92 \\
\hline 19 & 3.96 & 4.26 & 4.27 & 103 \\
\hline 20 & 3.35 & 3.65 & 3.38 & 88 \\
\hline 21 & 3.28 & 3.18 & 3.08 & 98 \\
\hline 22 & 2.80 & 2.60 & 2.62 & 102 \\
\hline 23 & 3.85 & 3.76 & 3.75 & 70 \\
\hline 24 & 2.70 & 2.62 & 2.80 & 80 \\
\hline 25 & 3.68 & 3.59 & 3.47 & 91 \\
\hline 26 & 2.82 & 2.82 & 2.81 & 105 \\
\hline 27 & 2.60 & 2.40 & 2.61 & 87 \\
\hline 28 & 3.27 & 2.98 & 3.18 & 94 \\
\hline Mean & 3.27 & 3.22 & 3.24 & 92 \\
\hline SEM & 0.18 & 0.19 & 0.18 & \\
\hline
\end{tabular}

Subj.: subject; $\mathrm{FEV}_{1}$ : forced expiratory volume in one second.

( $\mathrm{PC}_{20}$ and level of plateau), although the differences were not significant.

Individual values for $\mathrm{FEV}_{1}$ in each period before methacholine challenges are shown in table 2. Baseline FEV was not significantly different for all visits $(\mathrm{p}>0.05)$. Mean treatment compliance rate (table 2) was $89 \%$ in the placebo group and $92 \%$ in the budesonide group. No subject experienced an exacerbation for which prednisolone was prescribed.

Values of $\mathrm{PC}_{20}$ before and during the pollen season for the two treatment groups are shown in table 3. Geometric mean (range) methacholine $\mathrm{PC}_{20}$ decreased in the placebo group from $8.51(0.42-200)$ during the preseasonal assessment to $2.19(0.13-47.1)$ and to $1.78(0.10$ 35.0) $\mathrm{mg} \cdot \mathrm{ml}^{-1}$ in May and June, respectively $(\mathrm{p}<0.01)$. In the budesonide group, there was a decrease from 3.71 $(0.15-200)$ in the preseasonal assessment to $3.23(0.23-$ 200) and to $2.40(0.19-145.8) \mathrm{mg} \cdot \mathrm{ml}^{-1}$ in May and 
Table 3. - Individual values of $\mathrm{PC}_{20}$ methacholine $\left(\mathrm{mg} \cdot \mathrm{ml}^{-1}\right)$ before and during the pollen season for the two treatment groups

\begin{tabular}{|c|c|c|c|}
\hline \multirow{2}{*}{$\begin{array}{l}\text { Subj. } \\
\text { No. }\end{array}$} & \multirow{2}{*}{$\begin{array}{c}\text { Preseasonal } \\
\text { assessment }\end{array}$} & \multicolumn{2}{|c|}{ Seasonal assessment } \\
\hline & & May & June \\
\hline \multicolumn{4}{|l|}{ Placebo group } \\
\hline 1 & 0.80 & 0.16 & 0.33 \\
\hline 2 & 6.88 & 8.15 & 1.80 \\
\hline 3 & 1.67 & 0.80 & 1.09 \\
\hline 4 & 7.35 & 3.46 & 3.79 \\
\hline 5 & 0.74 & 0.28 & 0.20 \\
\hline 6 & 1.94 & 1.27 & 2.01 \\
\hline 7 & 3.87 & 1.33 & 1.67 \\
\hline 8 & 35.0 & 8.94 & 13.2 \\
\hline 9 & 200 & 8.64 & 11.2 \\
\hline 10 & 45.5 & 40.6 & 35.0 \\
\hline 11 & 5.72 & 2.11 & 3.12 \\
\hline 12 & 200 & 2.21 & 1.05 \\
\hline 13 & 200 & 47.1 & 14.8 \\
\hline 14 & 0.42 & 0.13 & 0.10 \\
\hline 15 & 7.72 & 0.91 & 0.42 \\
\hline Geometric mean & 8.51 & 2.19 & 1.78 \\
\hline \multicolumn{4}{|c|}{ Budesonide group } \\
\hline 16 & 200 & 200 & 145.8 \\
\hline 17 & 1.33 & 0.89 & 0.76 \\
\hline 18 & 1.80 & 1.73 & 2.76 \\
\hline 19 & 0.36 & 0.35 & 0.63 \\
\hline 20 & 0.16 & 0.41 & 0.76 \\
\hline 21 & 3.95 & 23.3 & 2.20 \\
\hline 22 & 4.99 & 1.59 & 2.99 \\
\hline 23 & 200 & 1.73 & 1.88 \\
\hline 24 & 6.59 & 7.23 & 1.22 \\
\hline 25 & 200 & 200 & 43.7 \\
\hline 26 & 0.43 & 1.70 & 1.74 \\
\hline 27 & 0.15 & 0.23 & 0.19 \\
\hline 28 & 3.09 & 3.06 & 3.05 \\
\hline Geometric mean & 3.71 & 3.23 & 2.40 \\
\hline
\end{tabular}

Subj.: subject; $\mathrm{PC}_{20}$ : provocative concentration of agonist causing a $20 \%$ fall in forced expiratory volume in one second.

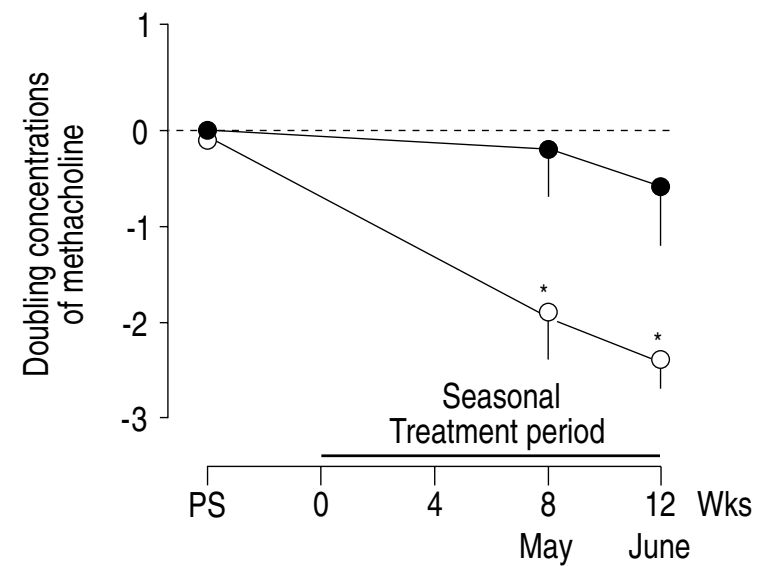

Fig. 1. - Mean \pm SEM change in $\mathrm{PC}_{20}$ (doubling concentrations of methacholine) during the pollen season for the two treatment groups.

$\longrightarrow$ - budesonide; ———: placebo. PS: preseasonal assessment; $\mathrm{PC}_{20}$ : provocative concentration producing a $20 \%$ fall in $\mathrm{FEV}_{1} ; \mathrm{FEV}_{1}$ : forced expiratory volume in one second. *: $\mathrm{p}<0.05$ compared to the budesonide group.

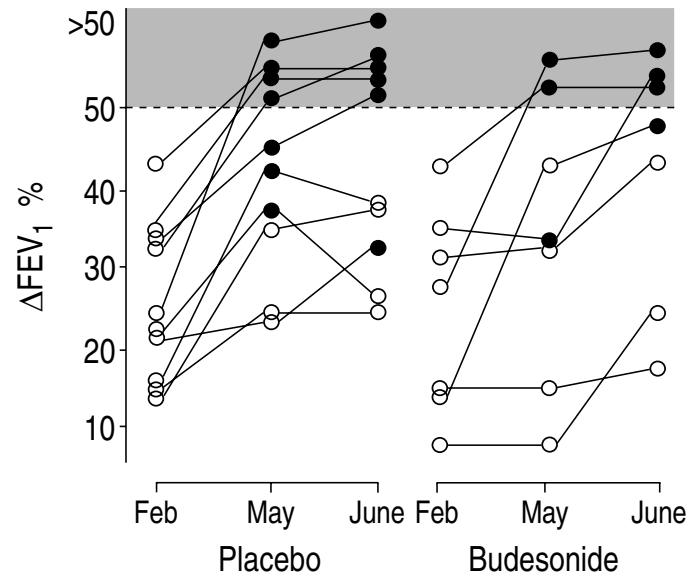

Fig. 2. - Maximal percentage fall in forced expiratory volume in one second $\left(\triangle \mathrm{FEV}_{1}\right)$ during each period in 10 subjects of the placebo group and 7 subjects of the budesonide group in whom plateau was detected during the preseasonal period. - - - : with plateau; - - - : without plateau. Shaded area: $\Delta>50 \%$.

June, respectively ( $\mathrm{p}>0.05)$. Between-group analysis (fig. 1) showed that in the budesonide group, the $\mathrm{PC}_{20}$ decreased by (mean \pm SEM) $0.19 \pm 0.60$ and $0.63 \pm 0.64$ doubling concentrations in May and June, respectively, as compared with $1.95 \pm 0.44$ and $2.25 \pm 0.52$ doubling concentrations in the placebo group $(\mathrm{p}<0.05)$.

In the placebo group, a maximal response plateau on the concentration-response curves was detected in 10 subjects during the preseasonal assessment, in three subjects in May $(p<0.05)$, and in four individuals in June $(\mathrm{p}<0.05)$. In the budesonide group, seven subjects showed plateau during the preseasonal assessment, four in May and three in June $(\mathrm{p}>0.05)$. The proportion of subjects (fig. 2) who lost the plateau after natural pollen exposure was not different in each group $(\mathrm{p}>0.05$, power $=65 \%$ ). Moreover, in five subjects who reached a maximal response plateau in all three periods, the level of plateau increased (fig. 3) during the seasonal assessment both in the placebo group (two subjects) and in the budesonide group (three subjects).

\section{Discussion}

In this study, we have shown that in pollen-sensitive subjects with mild asthma, treatment with inhaled budesonide blocks the effects of natural allergen exposure on the methacholine threshold value, and yet has no effect on changes in the maximal response plateau. Furthermore, this study confirms and extends earlier observations $[1,9]$ that natural antigenic exposure is associated with significant modifications both in the threshold $\left(\mathrm{PC}_{20}\right)$ and shape (maximal response plateau) of the concentration-response curves to inhaled methacholine.

In pollen-sensitive asthmatic subjects, natural exposure to pollen has been shown $[1,2]$ to decrease the threshold value of the dose-response curves to inhaled pharmacological agents. In a previous article, we reported that, in pollen-sensitive asthmatic patients, the cessation of exposure to pollen is associated with a significant decrease of the maximal response-plateau level to inhaled 

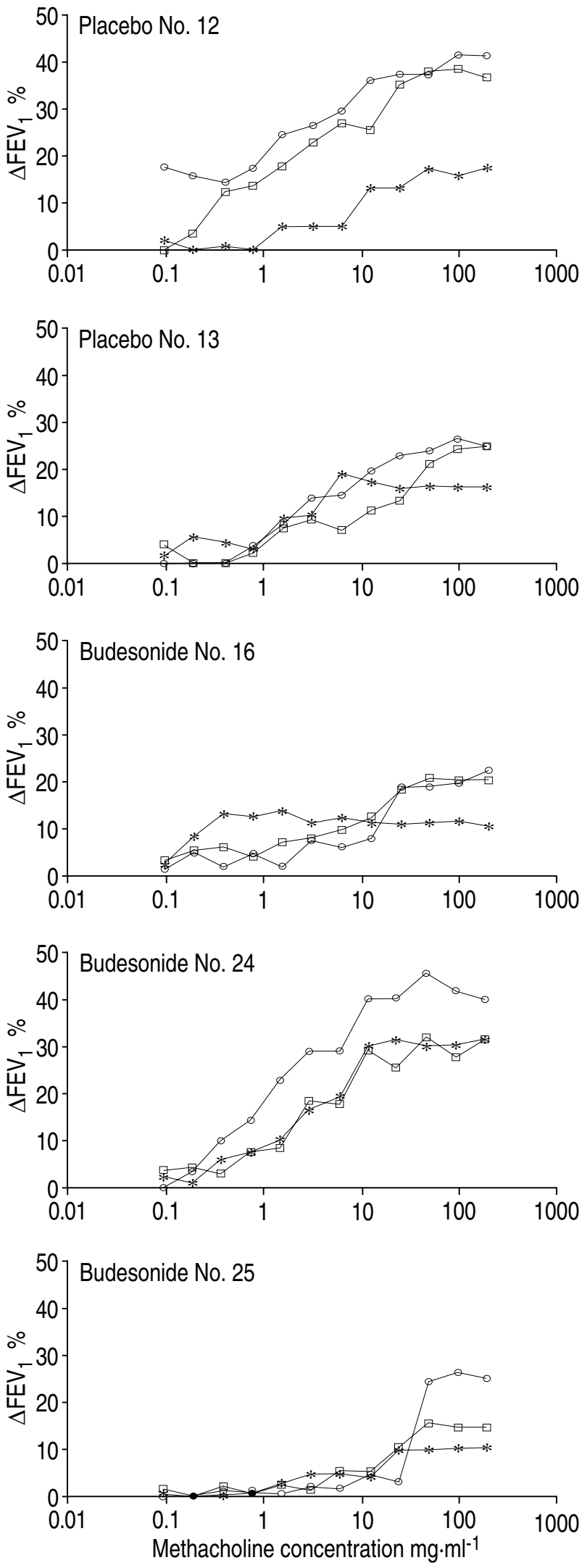

Fig. 3. - Concentration-response curves to methacholine in subjects who reached a maximal response plateau in all three challenges. The level of plateau increased during the pollen season in two subjects of the placebo group (Nos. 12 and 13) and in three subjects of the budesonide group (Nos. 16, 24 and 25). * - : preseasonal; - $\square-$ : May; - - : June. For abbreviations see legend to figure 2. methacholine [9], but this is the first study to document that natural pollen exposure causes the loss of the plateau in a considerable number of subjects.

A primary goal of this investigation was to determine the effect of inhaled budesonide on modifications of concentration-response curves to inhaled methacholine after natural allergen exposure. Increased airway responsiveness has been shown [18-21] after allergen-induced early and/or late asthmatic reactions in the laboratory. Moreover, the development of a late asthmatic response is preceded by an increased airway responsiveness [22], suggesting that the airway changes that increase responsiveness start before the late asthmatic reaction is clinically evident. Drugs, such as inhaled steroids [23, 24], sodium cromoglycate [8], and nebulized salbutamol [25] have been shown to prevent increases in airway responsiveness following exposure to specific allergens in the laboratory. However, provocation with nebulized allergen extract is entirely different from natural exposure to pollen grains. Under conditions of natural exposure during a pollen season, the allergen load may be greater and the duration of exposure is longer. Therefore, a single inhalation of an allergen in the laboratory can cause a mild increase in nonspecific airway responsiveness, whereas repeated allergen exposures, such as exposures that occur during the pollen season, can cause greater increases in airway responsiveness.

In a study by BONER et al. [26], it was observed that a 2 month treatment with beclomethasone dipropionate increased the methacholine $\mathrm{PC}_{20}$, even during a period of maximal allergen exposure. Moreover, a 7 day treatment with oral methylprednisolone $\left(16 \mathrm{mg} \cdot \mathrm{day}^{-1}\right)$ was shown [2] to reverse the seasonal decrease in provocative dose of agonist causing a $20 \%$ fall in $\mathrm{FEV}_{1}\left(\mathrm{PD}_{20}\right)$ carbachol in patients allergic to grass pollen. This suggested that the decrease in the threshold value observed during the period of allergen exposure could be reversed or prevented by oral and (probably) by inhaled steroid therapy. Recently, CORREN et al. [5] showed that treatment with nasal beclomethasone dipropionate prevented the decrease in methacholine $\mathrm{PC}_{20}$ associated with seasonal allergen exposure in pollen-sensitive patients with mild asthma, but this was not confirmed in a study by ARmitage et al. [27]. To the best of our knowledge, there are no studies that have investigated the effects of treatment with inhaled corticosteroids on the increase in airway responsiveness during the pollen season in pollensensitive asthmatic subjects. The results of our study demonstrate that in pollen-sensitive asthmatic patients, inhaled budesonide abolishes the effects of natural allergen exposure on the threshold response to inhaled methacholine. Interestingly, this was independent of any improvement in spirometry.

On the other hand, airway responsiveness to pharmacological agonists is usually measured in terms of the $\mathrm{PD}_{20}$ or $\mathrm{PC}_{20}$ histamine or methacholine. Beneficial effects of inhaled corticosteroids on threshold response to inhaled pharmacological agents have already been observed in asthmatic subjects [28, 29]. However, bronchial hyperresponsiveness is an in vivo phenomenon, in which the concentration-response curve shows three characteristics 
[7]: decreased threshold value; steepened slope; and increased maximum bronchoconstriction. The only functional characteristic that can limit the degree of airway obstruction in asthmatic patients is a plateau at mild degrees of airway narrowing and, thus, the effect of drugs on the maximal response plateau is considered to be relevant [30]. It has been shown [31] that in asthmatic subjects not exposed to the relevant allergens, the maximal response can be altered by inhaled budesonide without changing the threshold of the dose-response curve. Moreover, although the plateau correlates with the threshold value [32], changes in the characteristics of the doseresponse curve may be at least partially independent of each other [7]. In our placebo group, the increase or loss of the plateau during the pollen season was associated with a significant decrease of the $\mathrm{PC}_{20}$. However, budesonide protects against the seasonal modifications in the threshold, but has no effect on pollen-induced changes in the maximal response plateau. This supports the hypothesis $[31,33]$ that the plateau and the threshold response to inhaled methacholine are not modulated by the same mechanisms.

Although, in this study, it was not possible to assess the clinical benefit of inhaled budesonide on seasonal exacerbations of asthma in pollen-sensitive subjects, our observations are relevant to the pharmacological management of pollen-induced asthma. A drug which is able to reduce the effect of natural allergen exposure on the threshold value of the methacholine dose-response curve could be useful in the treatment of seasonal asthma [34]. However, it has been suggested that the asthma therapy should not be limited to increasing the threshold value, but also towards restoring the mechanism (plateau) which protects against excessive bronchoconstriction [30, 33]. Therefore, our results suggest that inhaled budesonide can be insufficient for protection of patients with seasonal asthma during the pollen season. However, the insufficient protection of inhaled budesonide on seasonal modifications in the plateau should be interpreted with caution. Although we intentionally chose patients with mild seasonal asthma in order to safely document a maximal response plateau to methacholine during the preseasonal assessment, this was not possible in 11 out of 28 patients at entry into the study. Moreover, plateau levels could be measured in only five patients in the three periods, and this small number of subjects precluded comparison of the plateau levels. We were not able to show a significant protection of inhaled budesonide against the pollen-induced modifications in the plateau, but this may be due to the limited number of subjects in whom plateau could be compared. The findings of our study would obviously need to be extended to a larger number of subjects with plateau.

In summary, in this study we have shown that in pollensensitive asthmatic subjects, a 12 week treatment with inhaled budesonide $\left(800 \mu \mathrm{g} \cdot \mathrm{day}^{-1}\right)$ blocks the effect of natural pollen exposure on the threshold value of the concentration-response curves to inhaled methacholine, but we were not able to show a significant protection against the pollen-induced modifications in the maximal response plateau.

\begin{abstract}
Acknowledgements: The authors thank nurse B. Camps for her technical assistance, and Aristegui Lab., Bilbao, Spain, for supplying the drugs.
\end{abstract}

\section{References}

1. Boulet $\mathrm{LPh}$, Cartier A, Thomson NC, Roberts RS, Dolovich J, Hargreave FE. Asthma and increases in nonallergic bronchial responsiveness from seasonal pollen exposure. J Allergy Clin Immunol 1983; 71: 399-406.

2. Sotomayor H, Badier M, Vervloet D, Orehek J. Seasonal increase of carbachol airway responsiveness in patients allergic to grass pollen. Reversal by corticosteroids. Am Rev Respir Dis 1984; 130: 56-58.

3. Löwhagen O, Rak S. Modification of bronchial hyperreactivity after treatment with sodium cromoglycate during pollen season. J Allergy Clin Immunol 1985; 75: 460-467.

4. Dorward AJ, Roberts JA, Thomson NS. Effect of nedocromil sodium on histamine airway responsiveness in grass pollen-sensitive asthmatics during the pollen season. Clin Allergy 1986; 16: 309-315.

5. Corren J, Adinoff AD, Buchmeier AD, Irvin ChG. Nasal beclomethasone prevents the seasonal increase in bronchial responsiveness in patients with allergic rhinitis and asthma. J Allergy Clin Immunol 1992; 90: 250256.

6. Woolcock AJ, Salome CM, Yan K. The shape of the dose-response curve to histamine in asthmatic and normal subjects. Am Rev Respir Dis 1984; 130: 71-75.

7. Moreno RH, Hogg JC, Paré PD. Mechanics of airway narrowing. Am Rev Respir Dis 1986; 133: 1171-1180.

8. Cockcroft DW, Murdock KY. Comparative effects of inhaled salbutamol, sodium cromoglycate and beclomethasone dipropionate on allergen-induced early asthmatic responses, late asthmatic responses, and increased bronchial responsiveness to histamine. J Allergy Clin Immunol 1987; 79: 734-740.

9. Prieto L, Bertó JM, López M, Peris A. Modifications of $\mathrm{PC}_{20}$ and maximal degree of airway narrowing to methacholine after pollen season in pollen-sensitive asthmatic patients. Clin Exp Allergy 1993; 23: 172-178.

10. American Thoracic Society. Definitions and classifications of chronic bronchitis, asthma and pulmonary emphysema. Am Rev Respir Dis 1962; 85: 762-768.

11. Subiza E, Subiza FJ, Jerez M. Incidencia granos de polen en Valencia. In: Sociedad Española de Alergología e Inmunología Clínica, eds. Tratado de Alergología e Inmunología Clínica, Madrid, Luzan 5 S.A. 1986; p. 351.

12. American Thoracic Society. Lung function testing: selection of reference values and interpretative strategies. Am Rev Respir Dis 1991; 144: 1202-1218.

13. Crapo RO, Morris AH, Gardner RM. Reference spirometric values using techniques and equipment that meet ATS recommendations. Am Rev Respir Dis 1981; 123: 659-664.

14. Quanjer $\mathrm{PhH}(\mathrm{Ed})$. Standardized lung function testing. Bull Eur Physiopathol Respir 1983; 19 (Suppl. 5): 195.

15. Cockcroft DW, Killian DN, Mellon JJA, Hargreave FE. Bronchial reactivity to inhaled histamine: a method and clinical survey. Clin Allergy 1977; 7: 235-243.

16. Prieto L, Marín J. Methacholine inhalation challenge. Practical consequences of using duplicate spirograms 
after each concentration. Ann Allergy 1993; 70: 487490.

17. Sterk PJ, Daniel EF, Zamel N, Hargreave FE. Limited bronchoconstriction to methacholine using partial flowvolume curves in nonasthmatic subjects. Am Rev Respir Dis 1985; 132: 272-277.

18. Cockcroft DW, Ruffin RE, Dolovich J, Hargreave FE. Allergen-induced increase in nonallergic bronchial reactivity. Clin Allergy 1977; 7: 503-513.

19. Cartier A, Thomson NC, Frith PA, Roberts R, Hargreave FE. Allergen-induced increase in bronchial responsiveness to histamine: relationship to the late asthmatic response and change in airway caliber. J Allergy Clin Immunol 1982; 70: 170-177.

20. Lai ChKW, Twentyman OP, Holgate ST. The effect of an increase in inhaled allergen dose after rimiterol hydrobromide on the occurrence and magnitude of the late asthmatic response and the associated change in nonspecific bronchial responsiveness. Am Rev Respir Dis 1989; 140: 917-923.

21. Boonsawat W, Salome ChM, Woolcock AJ. Effect of allergen inhalation on the maximal response plateau of the dose-response curve to methacholine. Am Rev Respir Dis 1992; 146: 565-569.

22. Durham SR, Craddock CF, Cookson WV, Benson MK. Increases in airway responsiveness to histamine precede allergen-induced late asthmatic responses. J Allergy Clin Immunol 1988; 82: 764-770.

23. De Baets FM, Goeteyn M, Kerrebijn KF. The effect of two months of treatment with inhaled budesonide on bronchial responsiveness to histamine and house dust mite antigen in asthmatic children. Am Rev Respir Dis 1990; 142: 581-586.

24. O'Shaughnessy KM, Wellings R, Gillies B, Fuller RW. Differential effects of fluticasone propionate on allergen-evoked bronchoconstriction and increased urinary leukotriene $\mathrm{E}_{4}$ excretion. Am Rev Respir Dis 1993; 147: 1472-1476.

25. Twentyman OP, Finnerty JP, Holgate ST. The inhibitory effect of nebulized albuterol on the early and late asthmatic reactions and increase in airway responsiveness provoked by inhaled allergen in asthma. Am Rev Respir Dis 1991; 144: 782-787.

26. Boner AL, Piacentini GL, Bonizzato C, Dattoli V, Sette L. Effect of inhaled beclomethasone dipropionate on bronchial hyperreactivity in asthmatic children during maximal allergen exposure. Pediatr Pulmonol 1991; 10: $2-5$.

27. Armitage JM, Lam KSF, Wilkinson I, Faux JA. Investigation of the tendency to wheeze in pollen sensitive patients. Clin Exp Allergy 1992; 22: 916-922.

28. Haahtela T, Järvinen M, Kava T, et al. Comparison of a beta ${ }_{2}$-agonist, terbutaline, with an inhaled corticosteroid, budesonide, in newly detected asthma. N Engl J Med 1991; 325: 388-392.

29. van Essen-Zandvliet EE, Hughes MD, Waalkens HJ, Duiverman EJ, Pocock SJ, Kerrebijn KF, and the Dutch chronic nonspecific lung disease study group. Effects of 22 months of treatment with inhaled corticosteroids and/or beta $_{2}$-agonists on lung function, airway responsiveness and symptoms in children with asthma. Am Rev Respir Dis 1992; 146: 547-554.

30. Macklem PJ. A hypothesis linking bronchial hyperreactivity and airway inflammation: implications for therapy. Ann Allergy 1990; 64: 113-116.

31. Bel EH, Timmers MC, Zwinderman AH, Dijkman JH, Sterk PJ. The effect of inhaled corticosteroids on the maximal degree of airway narrowing to methacholine in asthmatic subjects. Am Rev Respir Dis 1991; 143: 109-113.

32. Sterk PJ, Timmers MC, Dijkman JH. Maximal airway narrowing in humans in vivo. Histamine compared with methacholine. Am Rev Respir Dis 1986; 134: 714-718.

33. Sont JK, Bel EH, Dijkman JH, Sterk PJ. The long-term effect of nedocromil sodium on the maximal degree of airway narrowing to methacholine in atopic asthmatic subjects. Clin Exp Allergy 1992; 22: 554-560.

34. Woolcock AJ, Yan K, Salome CM. Effect of therapy on bronchial hyperresponsiveness in the long-term management of asthma. Clin Allergy 1988; 18: 165-176. 